\title{
EVOLUÇÃO DA ATIVIDADE ANTIOXIDANTE EM VINHOS TINTOS DE UVA BRS VIOLETA TRATADOS COM CARVALHO FRANCES E AMERICANO DURANTE ARMAZENAMENTO SOB DIFERENTES TEMPERATURAS
}

\author{
$\underline{\text { Tuany Yuri Kuboyama Nogueira }}{ }^{1}$; Roberto da Silva ${ }^{1}$; Isidro Hermosin Gutierrez ${ }^{2}$; Ellen Silva \\ Lago Vanzela ${ }^{1}$ \\ (tuh.kuboyama@hotmail.com)

\begin{abstract}
${ }^{1}$ Instituto de Biociências, Letras e Ciências Exatas, Universidade Estadual Paulista, Cristovão Colombo, 2265, Jardim Nazareth, 15054-000 São José do Rio Preto, São Paulo, Brasil

${ }^{2}$ Instituto Regional de Investigación Científica Aplicada, Universidad de Castilla-La Mancha, Avda. Camilo José Cela s/n, 13071 Ciudad Real, Spain
\end{abstract}

A cultivar BRS Violeta (BRS Rúbea x IAC 1398-21) tem se destacado devido ao elevado conteúdo de compostos fenólicos e ao potencial para elaboração de sucos e vinhos. Sua composição fenólica instiga novos estudos sobre como o tratamento do vinho de BRS Violeta com carvalho pode impactar na qualidade sensorial e valor nutricional do produto final. Uma técnica alternativa ao envelhecimento de vinho em barricas que vem sendo empregada é o envelhecimento dos vinhos, em tanques de aço inoxidável, adicionados de pedaços de carvalho. Assim, o objetivo deste trabalho foi avaliar a evolução da atividade antioxidante (AA) de vinhos de uva BRS Violeta após tratamento com dois tipos de carvalho granulado não tostado (americano e francês) ( $3 \mathrm{~g} / \mathrm{L}$ ), e posterior, armazenamento em estufas, tipo B.O.D., a 16,25 e $50^{\circ} \mathrm{C}$, durante 180 dias, em triplicata, simulando, respectivamente, o armazenamento nas vinícolas, o armazenamento nos estabelecimentos comerciais ou domicílios e para avaliar o envelhecimento acelerado dos vinhos. Análises periódicas $(0,5,15,30,60,90,130$ e 180 dias) de AA foram realizadas, de acordo com o método DPPH (2,2-difenil-1-picrilhidrazila), sendo os resultados expressos em mmol de equivalentes de trolox por litro de vinho. Observou-se um comportamento diferente entre os vinhos tratados com carvalho francês e com carvalho americano. Em ambos os casos, o controle a $16{ }^{\circ} \mathrm{C}$ apresenta os maiores valores de AA após 180 dias, com um aumento progressivo e lento, mas mantendo ao longo do tempo. Já os vinhos tratados com carvalho francês, a qualquer temperatura, e com os vinhos controles armazenados a 25 e $50^{\circ} \mathrm{C}$, apresentaram valores praticamente indiferenciáveis de AA, porém sendo todos menores que o controle a $16{ }^{\circ} \mathrm{C}$. Observa-se assim que a adição do carvalho francês não diminuiu a $\mathrm{AA}$ do vinho, exceto ao armazenamento a temperatura mais baixa $\left(16^{\circ} \mathrm{C}\right)$. Por outro lado, nos vinhos tratados com carvalho americano houve diminuição da sua AA após 180 dias. Este resultado pode ser devido ao fato do carvalho francês apresentar maior conteúdo de elagitaninos quando comparado ao carvalho americano. Estes compostos podem atuar como antioxidantes naturais e proteger outros compostos do vinho contra oxidação, devido sua grande capacidade de reagir com o oxigênio. Conclui-se que é mais aconselhável adicionar carvalho de origem francesa ao vinho de uva BRS Violeta visando melhor suas propriedades bioativas.

Palavras-chave: vinho; uva BRS Violeta; carvalho granulado; capacidade antioxidante. 